\title{
Animal-rights activists invade Europe
}

A rash of vandalism, intimidation and arson across continental Europe in 2008 is evidence of a worrying new wave of animal-rights extremism being exported from Britain, experts say.

In early January, threats led to a Dutch developer withdrawing from a new, $€ 60$ million (about US\$89 million) biomedical research park in Venray, the Netherlands. A month later, Hasselt University's Biomedical Research Institute in Diepenbeek, Belgium, was set on fire. And in Barcelona in Spain, vandals targeted the offices of biomedical-research firm Novartis.

The pattern "is quite clear-cut", according to Simon Festing, director of the Research Defence Society, a London-based group representing medical researchers. Festing says that he believes new, more stringent enforcement in the United Kingdom has led many extremists to move their activities overseas. "Activists are not finding it easy here," he says. "So they're just going across to Europe."

Over the past year, the United Kingdom has cracked down on animal-rights activists who break the law. Last May, police carried out Operation Achilles that led to charges against

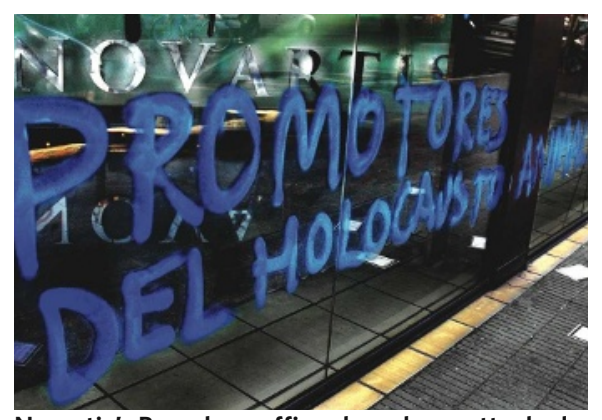

Novartis's Barcelona offices have been attacked.

16 activists. A trial involving several of them is expected to begin later this year.

Neither Interpol nor Europol, which coordinates European police activities, have firm statistics on extremist acts, but anecdotal evidence suggests that Britain's tougher law enforcement has led to a rise in activities on the continent. "It's been going on for years, but it's become worse," says Robert Janssen, the managing director of the Netherlands' biotechnology industry association NIABA in Leidschendam. Janssen estimates that Dutch researchers and institutions have received more than 200 threats in the past year.
It has come as a shock to some in the scientific community. "We've never had problems before," says Piet Stinissen, director of the Biomedical Research Institute at Hasselt University. On 1 February, the Institute was set ablaze, causing around $€ 100,000$ in damages. The fire was believed to be caused by the Animal Liberation Front, an extremist group. Stinissen, who has been at the University since 1994, says that he cannot remember a single previous incident of extremism.

Andrew Jackson, deputy head of security at Novartis in Basel, Switzerland, says that industry is also being affected. On 9 February, Novartis's offices in Barcelona were vandalized during a protest, and Jackson says that there has been an overall increase in both legal demonstrations and illegal acts. "We've had to increase the security of some of our facilities in Europe," he says. Novartis says that incidents outside the United States and United Kingdom rose by nearly $50 \%$ last year to 97 . There have been 15 events so far this year.

Jackson believes that the protests and criminal acts are being fuelled in part by British activists travelling abroad. "There is a perception that EU law enforcement has something

\section{Acclaimed photo was faked}

An award-winning photograph of a herd of endangered Tibetan antelopes apparently undisturbed by a passing train on the controversial Qinghai-Tibet railway has been exposed as a fake. The image was widely hailed in China as a symbol of harmonious co-existence between man and nature and strong testimony against any adverse effect of the new railway on the animals.

Photographer Liu Wei-qiang admitted the fabrication last week after comments on the Chinese online photography forum Without Fear questioned the picture's authenticity. Liu was promptly dismissed from the Daqing Evening News, based in Harbin, Heilongjiang province, where he was the deputy director of its photography department. The newspaper has also issued a public statement apologizing for the incident and announcing the resignation of its chief editor.

"The train was real, and so were the antelopes," said Liu in a posting on the photography forum. "But the magic moment just didn't happen even after I had waited for two weeks." Therefore, he decided to merge together one picture of a passing train with another of the migrating animals "to raise the public awareness of antelope protection". The merged picture was published by more than 200 media outlets around the world and won Liu a bronze medal in the 2006 Most Influential News Photos of the Year competition, sponsored by CCTV, China's state television.

Yang Xin, president of Green River, a nongovernmental environmental organization based in Chengdu, Sichuan province, met Liu on the Tibetan plateau in 2006. He says that he was surprised by the photographer's luck in seeing the train and animals passing on the same spot. "It is probably a one-in-athousand opportunity," he said.

"The truth is probably the opposite of what the picture was trying to claim," says Su Jian-ping, a zoologist at the Northwest Institute of Plateau Biology, Chinese Academy of Sciences, in Xining, Qinghai province. Su is sceptical of the government's

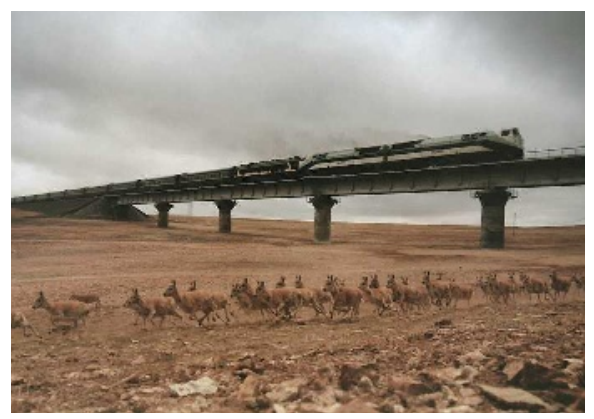

The 'photo' was actually a merger of two images.

claim that the railway has no impact on the antelopes' migration patterns. The antelopes are shy creatures and particularly prone to disturbances, he says, having spent years on the plateau studying their behaviour. There is no such a thing as "harmonious co-existence" between the train and antelopes, he adds. "You just don't see them together."

Yang describes Liu's behaviour as "totally inexcusable", and says that it has tainted the field of wildlife conservation. "Liu fabricated and supplied the image the government badly wanted to see, which may not have reflected the reality." 
of a soft touch," he says. Jackson says that he has noticed a correlation between availability of budget flights to Basel and extremist activity. "It makes for a fun weekend," he notes wryly.

But not everyone agrees that the British crackdown is behind increased activity elsewhere in Europe. Activists do occasionally go abroad to protest, says Amanda Richards, a spokesperson for SPEAK, an animal-rights group based in Northampton, UK, which has led a campaign against a primate laboratory at Oxford University (Nature 438, 716; 2005). But she believes that the rise in Europe is due primarily to rising awareness on the continent. "It's mainly people in the countries themselves," she says. SPEAK has been contacted by several individuals and groups in Europe who want to organize events against animal testing, she adds.

Janssen says that in the Netherlands at least, the government now appears to be taking animal-rights extremism more seriously. On 12 February, the Dutch parliament passed a motion to support the use of animal testing and condemning extremist acts. Janssen says that he hopes the motion will be followed by more rigorous lawenforcement.

Geoff Brumfiel

The incident is not the first faked image to be used in the environmental arena. Last October, the Shanxi Forestry Department publicized two photographs of a South China tiger in the wild, which caused much excitement as the species had been considered functionally extinct. According to the verdicts of six experts in forensics and image verification, the pictures were fake, probably taken of a cardboard tiger planted in the woods. The farmer claiming to have taken the snaps stands by their authenticity, and the local government is yet to release the report of its own investigation.

"These are hardly isolated incidences," say Qiu Ren-zong, an ethicist at the Institute of Philosophy, Chinese Academy of Social Sciences, in Beijing. "China suffers from a serious lack of accountability with rampant fraud and corruption in its political, economic and academic life." Real transparency and an effective check-and-balance system must be put in place if China is to move forward, he says. Jane Qiu

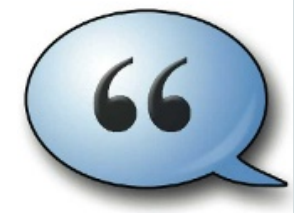

HAVE YOUR SAY

Comment on any of our news stories, online. www.nature.com/news

\section{Revamp for NIH grants}

Scientists applying to the US National Institutes of Health (NIH) for grants could be accelerated through the painful peer-review process under recommendations proposed on 21 February aimed at overhauling the decades-old system.

Currently, a grant proposal can take 18 months to pass through the system, waiting in line behind older applications, most of which must go back and forth to the applicants for rewrites and amendments before approval. The new proposals aim to change this, at least for the best grants, by eliminating what they call the 'special status' of amended applications that often sees them funded before promising first-time proposals.

"It's a system that rewards persistence over brilliance sometimes. And we really want to change that," says NIH director Elias Zerhouni, whose advisory committee was presented with a 78-page draft report of recommendations.

Applicants would also no longer have to respond to reviewers' comments as part of their second or third attempts with the same application. Nor would reviewers considering amended applications any longer see previous reviewers' comments. That way, they "will not be biased in any way by any prior review", says Lawrence Tabak, director of the NIH's dental institute who co-chaired the two advisory panels charged with reviewing the system.

The panels - an internal working group of senior NIH officials and another of external scientists - were asked last June to come up with recommendations to ensure that the $\$ 29.3$ billion agency funds "the best science, by the best scientists, with the least administrative burden".

Other recommendations include substantially shortening the 25-page applications by minimizing the preliminary data and methodological detail required. They say that the NIH should consider reviewing early-career investigators in a separate pool against each other, rather than throwing them up against established veterans. And they advise that the poorest-quality applications (not just early- career ones) should be bluntly coded NRR - "not recommended for resubmission".

In a bid to share finite riches, but one that seems bound to stir controversy among superstar grantees, the panels would like to see the NIH require principal investigators to commit at least $20 \%$ of their time to work on any single grant that is funded. For the vast majority of grantees, who receive one or two grants, that should be possible; for the 783 grantees awarded four or more grants, it will clearly have consequences.

Several scientists not involved in the process say they are pleased with the scope and broadmindedness of the recommendations. "The focus on making the system work better is exactly right," says David Korn, chief scientific officer of the Association of American Medical Colleges and a former dean of the Stanford University School of Medicine. "And it's really terrific that the NIH has decided to go at it very explicitly and very boldly."

"It was pretty obvious that this was going to be a serious effort at improving the system, and I think they've come through," says Katherine Wilson, a cell biologist at the Johns Hopkins University School of Medicine in Baltimore, Maryland, who testified to the external panel last summer on behalf of the American Society for Cell Biology.

Wilson did some back-of-the-envelope sums based on NIH numbers in the draft report (see graph). If every grantee with four or more NIH grants was reduced to holding two grants, she calculates, "that boosts the number of available grants by 1,852 - that's $5 \%$. It's the difference between the current grim situation and making the system work again."

Others contend that the recommendations, however enterprising, will not improve a situation that has seen NIH funding essentially frozen since 2003. Zerhouni will now consider the report and plans to assemble an implementation team in the next two months.

Meredith Wadman

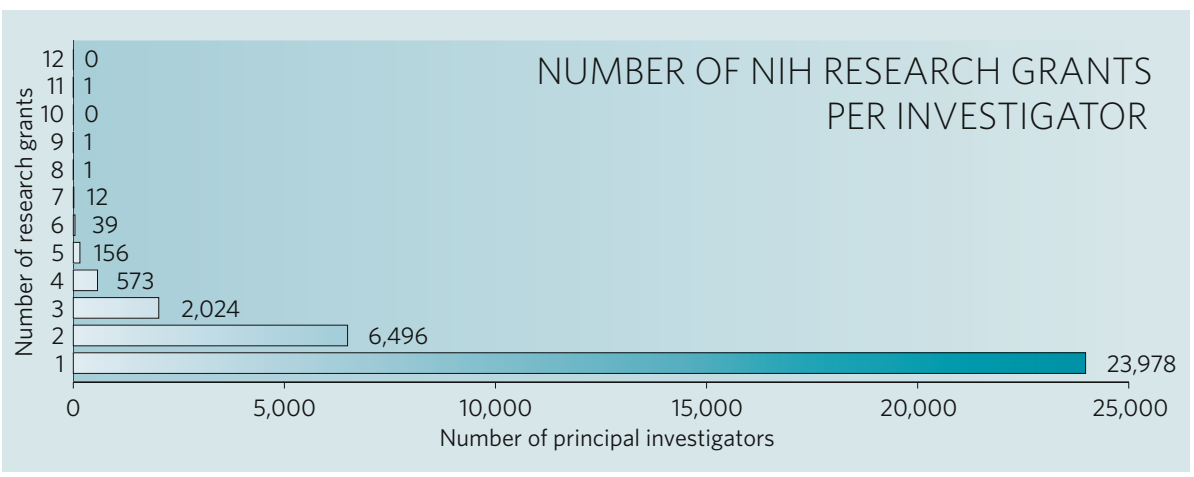

